\title{
Adhesive B-doped DLC films on biomedical alloys used for bone fixation
}

\author{
A A AHMAD* and A M ALSAAD \\ Department of Physical Sciences, Jordan University of Science and Technology, P.O. Box 3030, Irbid 22110, Jordan
}

MS received 5 February 2007

\begin{abstract}
The long-term failure of the total hip and knee prostheses is attributed to the production of wear particles at the articulating interface between the metals, ceramics and polymers used for surgical implants and bone-fixtures. Therefore, finding an adhesive and inert coating material that has low frictional coefficient should dramatically reduce the production of wear particles and hence, prolong the life time of the surgical implants. The novel properties of the non-toxic diamond-like carbon (DLC) coatings have proven to be excellent candidates for biomedical applications. However, they have poor adhesion strength to the alloys and biomaterials. The addition of a thin interfacial layer such as $\mathrm{Si}$, $\mathrm{Ti}$, $\mathrm{TiN}, \mathrm{Mo}$ and $\mathrm{Cu} / \mathrm{Cr}$ and/or adding additives such as $\mathrm{Si}$, F, N, O, W, V, Co, Mo, Ti or their combinations to the DLC films has been found to increase the adhesion strength substantially. In our study, grade $316 \mathrm{~L}$ stainless steel and grade 5 titanium alloy (Ti-6Al-4V) were used as biomaterial substrates. They were coated with DLC films containing boron additives at various levels using various $\mathrm{Si}$ interfacial layer thicknesses. The best film adhesion was achieved at $8 \%$ and $20 \%$ on DLC coated $\mathrm{Ti}-6 \mathrm{Al}-4 \mathrm{~V}$ and grade $316 \mathrm{~L}$ substrates, respectively. It has been demonstrated that doping the DLC with boron increases their adhesion strength to both substrates even without silicon interfacial layer and increases it substantially with optimum silicon layer thickness. The adhesion strength is also correlated with the hydrogen contents in the B-DLC films. It is found to reach its maximum value of $700 \mathrm{~kg} / \mathrm{cm}^{2}$ and $390 \mathrm{~kg} / \mathrm{cm}^{2}$ at $2 / 7$ and $3 / 6$ for $\mathrm{CH}_{4} / \mathrm{Ar}$ partial pressures (in mTorr ratio) for Ti-6Al-4V and 316 $\mathrm{L}$ substrates, respectively.
\end{abstract}

Keywords. Boron-doped DLC; biomedical materials; adhesion strength; stainless steel; titanium alloys.

\section{Introduction}

Biomaterials are used in vast range of biomedical applications such as surgical implants including joints, limbs, total hips, knees, artificial arteries, skins, dentures, heart valves, intra uterine devices (IUDs), pacemaker leads and cardiovascular nets. Biomaterials are classified according to their role in biomedical applications into three main types: (i) inert or almost inert biomaterials which stimulate no tissue response, (ii) active biomaterials which encourage bonding to surrounding tissues such as bone grafting and (iii) degradable or resorbable biomaterials which incorporate into surrounding tissues or even dissolve completely after a period of time. The metals and their alloys such as grade $316 \mathrm{~L}$ stainless steel and grade 5 titanium alloy ( $\mathrm{Ti}-$ $6 \mathrm{Al}-4 \mathrm{~V})$ are good examples of almost inert biomaterials and electrochemically passive. Commercial pure titanium (Ti) and titanium alloys (Ti-6Al-4V) are widely used as surgical and dental materials due to their excellent mechanical and physical properties. They are mainly used as permanent implants because of their low density $\left(4.51 \mathrm{~g} / \mathrm{cm}^{3}\right.$

*Author for correspondence (sema@just.edu.jo) and $4.40 \mathrm{~g} / \mathrm{cm}^{3}$, respectively), proper mechanical Young's modulus (110 GPa and $106 \mathrm{GPa}$, respectively) and good corrosion properties. Moreover, they are almost biologically inert (Franks 1989; Davidson et al 1994; Harris 1994; Czernuszka 1996; Bonfield and Tanner 1997; Gogolewski and Mainil-Varlet 1997; Breusch and Kuhn 2003). However, the biomedical applications of titanium alloys are limited by their relatively low wear and low chemical resistance in some biological environments (Czarnowska et al 2000; Czyrska-Filemonowicz et al 2003). Stainless steel, such as grade $316 \mathrm{~L}$, is also a biomedical metallic composite that contains many elements in which iron is dominant. It has higher density $\left(8 \mathrm{~g} / \mathrm{cm}^{3}\right)$, Young's modulus (200 GPa) and low static rate corrosion compared with titanium and titanium alloys. Devices made of stainless steel are used as temporary implants in orthopedic application such as fracture plates, bone screws and hip nails. A very sophisticated method of surface finishing such as surface passivation is needed to produce an iron-free surface when stainless steel is implanted in the human body. However, most often surface-contamination occurs when stainless steel is scrapped with carbon steel tools or fixtures. Contaminants could be free iron, cast iron, mild iron, carbon steel or low alloy steel particles in the case of stainless 
steel and free titanium, aluminum and vanadium species in the case of Ti-6Al-4V (Venugopalan and Gaydon 1999). Whatever is the case, metallic and metallic alloy implants have proved to release positive ions (cations) into the body under the test of electrolytic and proteins addition. These cations could be of ultimate threat to the body. The release of wear particles or elements from alloys could cause biochemical interactions with the surrounding tissues and blood cells which ultimately causes implant-surface corrosion and hence, body-skin inflammation (Venugopalan and Gaydon 1999). Williams and co-workers demonstrated that the addition of protein to stainless steel and commercial pure titanium increased their static corrosion rates but did not affect the titanium alloy (Ti-6Al-4V) (Clark and Williams 1982; Williams et al 1987).

Diamond-like carbon (DLC) coatings, or the so called amorphous hydrogenated carbon a-C:H, have been used for titanium alloys or the stainless steel implants to avoid unwanted surface interactions with the in vivo blood and tissues due to their novel non-toxic, inert, low frictional coefficient and biocompatibility properties ( $\mathrm{Li}$ and $\mathrm{Gu}$ 2002). DLC has been shown to have outstanding tribological properties in many technical applications due to a DLC phase transformation into graphite forming an interface layer (solid lubricant) at the articulating interface with the attached components. The DLC coatings have an excellent haemocompatibility, which is expressed in decreased thrombus formation. When exposed to blood, an increased ratio of albumin to fibrinogen absorption, as well as, decreased platelet activation are observed on coated surfaces (Hauert 2003). However, unfortunately DLC has a poor adhesive property to biomedical metals and alloys such as titanium and stainless steel (Lee et al 1992; Miyoshi et al 1992; Harris et al 1993). Many approaches have been conducted to increase the DLC adhesion strength in biomedical implants. A substantial increase in the adhesion strength for the DLC coating to grade- $5 \mathrm{Ti}-6 \mathrm{Al}-4 \mathrm{~V}$ titanium alloy was achieved by sputter cleaning to the substrate surface and by introducing a thin interfacial $\mathrm{Si}$ layer (Grill et al 1990; Ianno et al 1995). Interfacial layers such as $\mathrm{Ti}, \mathrm{TiC}$, TiN, Mo and $\mathrm{Cu} / \mathrm{Cr}$ were also used to strengthen the bonds between the substrate and the DLC coatings (He et al 1955; Bentzon 1994; Deng and Braun 1996; Ronkainen 1996; Taube et al 1996). Some other researchers have introduced additives such as $\mathrm{Si}, \mathrm{F}, \mathrm{N}, \mathrm{O}$, $\mathrm{W}, \mathrm{V}, \mathrm{Co}, \mathrm{Mo}, \mathrm{Ti}$ and their combinations to the DLC films, while maintaining their amorphous phase, in order to improve their adhesion to the biomedical implants (Hauert 2003). Moreover, fabricating the DLC coating with a reactive magnetron sputter deposition process yields higher adhesion strength values compared to those produced by other methods such as plasma enhanced chemical vapour deposition (PECVD) (Ianno et al 1995). Consequently, processing and treatment of films in this manner yield DLC coatings that become good candidate for biomedical application.
The mechanical properties of the B-DLC polymer are believed to control the type of interfacial forces required for good adhesion. In order to achieve high adhesion, the interface has to sustain sufficient stress to introduce dissipative forms of deformation such as yield, crazing or flow in the polymer or alloy (Brown 2000). Polymers have rather different deformation processes than other materials, and acquire their toughness from their long chain nature. They are also known to have lower modulus and deformation resistance than other materials. Hence, deformation at a polymer-inorganic interface normally occurs within the polymer and failure often occurs within the polymer or at the interface. Therefore, it is the polymer, together with the interface chemistry, that often controls the adhesion. Failure within the polymer or at the interface is not always the case. It could occur within the inorganic material, particularly, within the weak oxide or hydroxide film on the metal. Therefore, good pre-treatment, such as polishing, wet cleaning and sputter etching have to be performed on the surface of the material in order to overcome the failure in the oxide or hydroxide surface layer.

In a previous study (Ianno et al 1995), the adhesion strength of the DLC coatings was improved to grade 5 titanium alloy (Ti-6Al-4V) substrate via introducing $\mathrm{Si}$ interfacial layer. In this study the investigation is extended to include grade $316 \mathrm{~L}$ stainless steel substrate. The enhancement of the DLC-substrate adhesion strength is conducted via three approaches. The DLC films were doped with boron additives to form B-DLC films in the first approach. The amount of boron content is achieved by varying the applied d.c. sputtering power. In the second approach, silicon interfacial layer with given thickness is introduced between the B-DLC coatings and the substrates. Finally, the hydrogen contents in the B-DLC films were allowed to vary through variation for the ratio of methane to argon $\left(\mathrm{CH}_{4} / \mathrm{Ar}\right)$ partial pressures. Although many physical properties of the films are of considerable importance to understanding the mechanism and chemistry of the over layer coatings, this study is dedicated mainly for investigating the adhesion strength as a function of $\mathrm{B} / \mathrm{C} \%$, hydrogen contents and silicon interfacial layer thickness.

\section{Experimental and biomaterials}

The adhesion strength, coefficient of friction, morphology, hardness and wear particle resistance properties of the boron-doped DLC depend mainly on the method of deposition and the parameters used in the process. All these physical properties, as well as others, determine the basic building measures for reliable over-coated biomaterials that are biocompatible and hence can extend the life of the implants for a longer time. Using the two-level factorial design approach, a selected group of screening experiments was conducted to produce B-DLC films on selected substrates. In this method, two parameters are 
allowed to vary in order to maximize the adhesion strength while fixing all the other parameters (Davies 1971; Box et al 1978; Grill et al 1990; Ianno et al 1995).

The non-balanced magnetron reactive d.c. sputter deposition technique was employed in fabricating both the silicon interfacial layers and the B-DLC coatings. Based on optimized conditions, the silicon films were deposited on clean substrates to produce the required film thickness. The commercial titanium alloy, grade $5 \mathrm{Ti}-6 \mathrm{Al}-4 \mathrm{~V}$ and grade $316 \mathrm{~L}$ stainless steel substrates were cut in almost similar sizes $(1 \times 1 \mathrm{~cm})$. They were then polished to a mirror finish, rinsed in deionized water, dried with dry air and then bathed in ultrasonic bathes using trichloroethane, acetone and methanol, respectively. Each bath in the cleaning process was performed for $5 \mathrm{~min}$. The samples were finally rinsed again with deionized water and dried with hydrogen-free dry air before they were inserted into the sputtering chamber. The sputtering system was usually loaded with single crystalline (100) silicon, cleaned $\mathrm{Ti}-6 \mathrm{Al}-4 \mathrm{~V}$ and $316 \mathrm{~L}$ substrates before the real silicon deposition took place. Applying a 125 Watt d.c. power to the sputter gun that contained a $99.999 \%$ pure silicon target under $7 \mathrm{mT}$ orr argon pressure produced silicon films of around $250 \mathrm{~nm}$ in $15 \mathrm{~min}$. Presputter cleaning process for $10 \mathrm{~min}$ was usually performed before silicon sputtering took place. During this process, a shutter was placed in front of the target in order to prevent any sputtered silicon particles from reaching the substrates. This step was made possible by generating the argon plasma while driving the substrate with radio frequency high enough to form a self-induced d.c. bias of $-100 \mathrm{~V}$. A set of silicon-coated substrates (Ti-6Al-4V and 316L) with proper silicon layer thickness was prepared using this method and this was used in the B-doped DLC films later. The thickness of the silicon films was measured by a mechanical stylus. The substrate-film step profile was performed by masking a small portion of the crystalline silicon substrate by a small drop of silver-paint prior to film deposition. After film deposition, the silver-paint drop was removed leaving a substrate-film step profile behind it. This substrate-film step was used for film thickness measurement. The silicon layer thicknesses were approximated by calibrating the system with the time needed for proper film thickness (deposition rate) and this was found to be accurate within $5 \%$ error.

Deposition of B-DLC films was achieved by the following procedure. The cryo-pumped chamber was normally evacuated to less than one micro Torr base-pressure. The sputtering gun used was a planar magnetron configured in a non-balanced shape which contains 4 " diameter boron carbide $\left(\mathrm{B}_{4} \mathrm{C}\right)$ target with $99.99 \%$ purity. The argon and methane $\left(\mathrm{CH}_{4}\right)$ gases were electronically controlled for the desired flow rates. The partial pressure of argon was first set to the desired value at fixed flow rate $\left(30 \mathrm{~cm}^{3}\right)$ by adjusting the gate valve of the sputtering system. The flow rate of methane gas was then adjusted so that the total pressure of the two gases was achieved ( 9 mTorr). The substrate holder, which is neither cooled nor heated, was placed three inches away facing the sputter target surface and made electrically floating. The self-heated substratetemperature was monitored during the deposition process and found to be $<60^{\circ} \mathrm{C}$ in all the runs. The substrate selfbiased potential was $<12$ d.c. $\mathrm{V}$ in all the runs. In order to vary the boron contents in the DLC films, the applied d.c. power was set to vary between 50 and $350 \mathrm{~W}$ in steps of $50 \mathrm{~W}$. Each set of the samples has proper substrates with proper silicon layer thickness $(0-350 \mathrm{~nm}$ in steps of $100 \mathrm{~nm}$ ). In the second group of the samples, the hydrogen contents in the DLC films were allowed to vary through variation of the ratio of methane to argon $\left(\mathrm{CH}_{4} / \mathrm{Ar}\right)$ partial pressures. The applied d.c. power was set at $150 \mathrm{~W}$ for all the prepared samples. This approach is correlated with respect to the silicon interfacial layer thickness, too. The adhesion strength is then measured against all these variables as will be seen in the next section. The DLC-films/ $\mathrm{Si}(100) /$ substrate samples were used for thin film thickness measurements as well as for evaluating the percentage of boron in the DLC (B/C at \%) by using the auger electron spectroscopic technique.

The adhesion strength of the B-DLC films on the substrates which are already precoated with silicon was measured by the Sebastian IV Thin Film Adhesion Strength System manufactured by Quad Group Inc. In this method, a metal slug precoated with epoxy supplied by the manufacturer was fastened perpendicular to the film surface. The samples including the slugs were inserted in a pre-heated furnace to $150^{\circ} \mathrm{C}$ for $1 \mathrm{~h}$ in order to cure the epoxy as recommended by the Quad Group. The heat of the furnace was allowed to increase and decrease gradually on the samples so that no sudden heating or cooling was applied to the epoxy. The samples were loaded into the system tester with a metal slug pointing downwards. An incremental downward load was applied to the slug until the film pulled away from the substrate. The threshold load was then recorded in units of $\mathrm{kg} / \mathrm{cm}^{2}$.

\section{Results and discussion}

Improving the adhesion strength of B-DLC films on the substrates is investigated thoroughly in different ways. Cleaning the substrates and using the method discussed previously, the adhesion strength increased by almost three times to that compared with the non-cleaned substrates. A period of $10 \mathrm{~min}$ pre-sputtering process has doubled the adhesion strength of the films. Doping DLC films with proper amount of boron was achieved by applying certain value of d.c. power to the sputtering gun of the deposition system. The relationship between the applied d.c. power and the $\mathrm{B} / \mathrm{C}$ at \% (evaluated from the auger electron spectroscopic scans) is found to be almost linear (up to $30 \%$ ) and is shown in figure 1 as related to the results given in table 1 (Ahmad 1996). 
Table 1. The adhesion strength $\left(\mathrm{kg} / \mathrm{cm}^{2}\right)$ as a function of applied power and silicon film thickness at self substrate temperature ( $\mathrm{rf}$ induced d.c. bias voltage $=-100 \mathrm{~V}$ and $\mathrm{CH}_{4} / \mathrm{Ar}=3 / 6 \mathrm{mTorr}$ ).

\begin{tabular}{|c|c|c|c|c|c|c|c|c|c|c|}
\hline \multirow[b]{2}{*}{$\begin{array}{l}\text { d.c. Power }(\mathrm{W}) \\
\equiv \mathrm{B} / \mathrm{C}(\text { at } \%)\end{array}$} & \multicolumn{5}{|c|}{$\begin{array}{l}\text { Adhesion strength }\left(\mathrm{kg} / \mathrm{cm}^{2}\right) \\
\text { Ti-6Al-4V titanium alloy substrate }\end{array}$} & \multicolumn{5}{|c|}{$\begin{array}{l}\text { Adhesion strength }\left(\mathrm{kg} / \mathrm{cm}^{2}\right) \\
\text { 316L stainless steel substrate }\end{array}$} \\
\hline & $\begin{array}{l}\text { No } \\
\text { silicon }\end{array}$ & $\begin{array}{l}50 \mathrm{~nm} \\
\text { silicon }\end{array}$ & $\begin{array}{l}150 \mathrm{~nm} \\
\text { silicon }\end{array}$ & $\begin{array}{l}250 \mathrm{~nm} \\
\text { silicon }\end{array}$ & $\begin{array}{l}350 \mathrm{~nm} \\
\text { silicon }\end{array}$ & $\begin{array}{l}\text { No } \\
\text { silicon }\end{array}$ & $\begin{array}{l}50 \mathrm{~nm} \\
\text { silicon }\end{array}$ & $\begin{array}{l}150 \mathrm{~nm} \\
\text { silicon }\end{array}$ & $\begin{array}{l}250 \mathrm{~nm} \\
\text { silicon }\end{array}$ & $\begin{array}{l}350 \mathrm{~nm} \\
\text { silicon }\end{array}$ \\
\hline $50 \equiv 1 \%$ & 152 & 405 & 523 & 534 & 521 & 132 & 156 & 182 & 185 & 183 \\
\hline $100 \equiv 3 \%$ & 197 & 498 & 589 & 578 & 565 & 145 & 178 & 239 & 242 & 245 \\
\hline $150 \equiv 7 \%$ & 234 & 665 & 687 & 665 & 644 & 189 & 240 & 251 & 256 & 254 \\
\hline $200 \equiv 11 \%$ & 255 & 612 & 654 & 634 & 620 & 210 & 268 & 289 & 290 & 350 \\
\hline $250 \equiv 17 \%$ & 263 & 564 & 620 & 589 & 567 & 250 & 280 & 345 & 350 & 349 \\
\hline $300 \equiv 25 \%$ & 221 & 573 & 564 & 540 & 540 & 279 & 298 & 359 & 368 & 365 \\
\hline $350 \equiv 30 \%$ & 187 & 533 & 543 & 523 & 530 & 286 & 321 & 378 & 383 & 377 \\
\hline
\end{tabular}

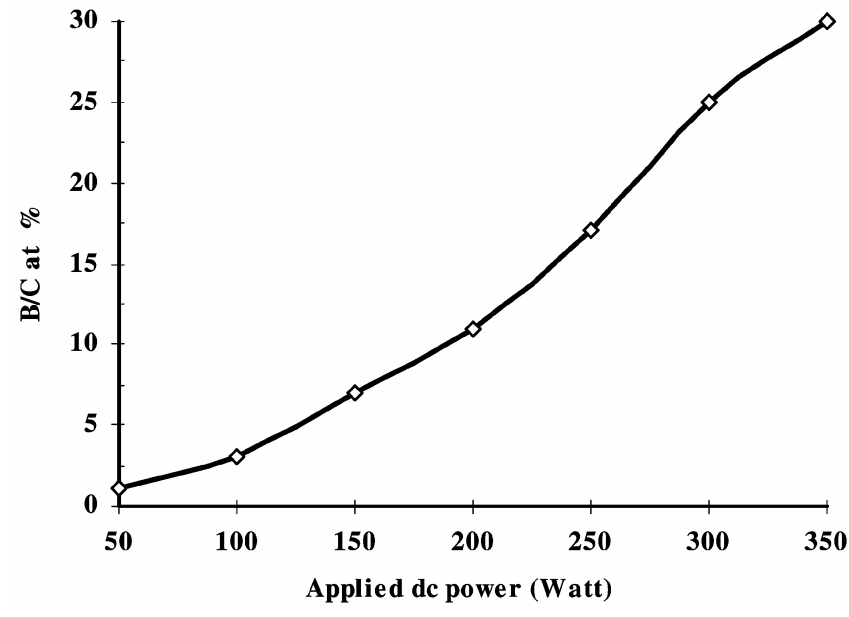

Figure 1. Boron/carbon ratio percentage (B/C at \%) as a function of applied power evaluated from the auger electron spectroscopic scans.

The deposition conditions for the first set of the sputter deposited B-DLC films on $\mathrm{Si} / \mathrm{Ti}-6 \mathrm{Al}-4 \mathrm{~V}$ and $\mathrm{Si} / 316 \mathrm{~L}$ substrates, at room temperature and fixed $\mathrm{CH}_{4} / \mathrm{Ar}=$ ( $3 \mathrm{mTorr} / 6 \mathrm{mTorr}$ ) partial pressures ratio for different Bcontents, are summarized in table 1 . The radio frequency induced d.c. bias voltage was maintained at $-100 \mathrm{~V}$ in all the runs. The applied d.c. power was fixed at constant value (corresponding to certain value of $\mathrm{B} / \mathrm{C}$ at $\%$ ), while the adhesion strength was measured for all the samples with different silicon interfacial layer thicknesses.

Table 2 summarizes the sputtering conditions for the second set of samples at fixed d.c. power $(150 \mathrm{~W})$ that is related to $\mathrm{B} / \mathrm{C}$ at $\%=8 \%$. The adhesion strength is evaluated at certain $\mathrm{CH}_{4} / \mathrm{Ar}$ partial pressures ratio as a function of silicon layer thickness. It was intended in this part of the experiment to investigate the role of hydrogen contents in DLC films by controlling the percentage of the reactive source of hydrogen $\left(\mathrm{CH}_{4}\right)$ related to the sputtering gas (Ar). Carbon hydrogenation plays an important role in fabricating DLC films of a structural phase ranging between amorphous and nanocrystalline DLC materials. Hence, the adhesion strength and residual stress are expected to correlate accordingly. Usually the applied and self-induced $\mathrm{rf}$ and d.c. biases on the substrate affect the hydrogen content in DLC films in addition to the presence of hydrogen source through the partial pressure of its gas carrier $\left(\mathrm{CH}_{4}\right)$ in the deposition system.

Although it is well known that the adhesion strength of pure DLC coating on stainless steel is higher than that on titanium and titanium alloy (Ti-6Al-4V) (Ianno et al 1995; Sheeja et al 2001), our study demonstrates that doping DLC films with boron increases their adhesion strength to titanium alloy (Ti-6Al-4V) to a value that is higher than that when deposited on grade 316L stainless steel. This result applies to all sputtering conditions shown in tables 1 and 2 for zero silicon interfacial layer thickness and agrees with the results obtained by Baker and co-workers (Baker et al 1997), while doping DLC films with more than $10 \%$ of boron additives. The enhancement of the surface hardness is attributed to the formation of strong Ti-B bonds at shallow and deep levels of depth profile caused by diffusion of boron inside the substrate surface.

The average adhesion strength of silicon on both substrates depends on the surface chemical cleaning as well as the presputtering process. The adhesion strength values for all silicon films on $\mathrm{Ti}-6 \mathrm{Al}-4 \mathrm{~V}$ and grade $316 \mathrm{~L}$ substrates were found to be on an average around 790 and $850 \mathrm{~kg} / \mathrm{cm}^{2}$, respectively regardless of their thicknesses. Therefore, all the pull test trials made over the BDLC/Si/Ti-6Al-4V and B-DLC/Si/grade 316L samples have shown that the B-DLC to Si contact tears up with the metallic slug rather than the Si to substrate contact. This observation was attributed to the strong adhesion of silicon to both substrates compared with that of the BDLC films to the silicon interfacial layer itself. This particular result is in complete contradiction with the previous experimental findings obtained for pure DLC performed in a previous work (Ianno et al 1995). In fact, it was pre- 
Table 2. The adhesion strength as a function of gas partial pressures ratio and silicon film thickness (d.c. power $=150 \mathrm{~W}$ ).

\begin{tabular}{|c|c|c|c|c|c|c|c|c|c|c|}
\hline \multirow[b]{2}{*}{$\begin{array}{l}\mathrm{CH}_{4} / \mathrm{Ar} \\
\text { (mTorr) }\end{array}$} & \multicolumn{5}{|c|}{$\begin{array}{l}\text { Adhesion strength }\left(\mathrm{kg} / \mathrm{cm}^{2}\right) \\
\text { Ti-6Al-4V titanium alloy substrate }\end{array}$} & \multicolumn{5}{|c|}{$\begin{array}{l}\text { Adhesion strength }\left(\mathrm{kg} / \mathrm{cm}^{2}\right) \\
\text { 316L stainless steel substrate }\end{array}$} \\
\hline & $\begin{array}{l}\text { No } \\
\text { silicon }\end{array}$ & $\begin{array}{l}50 \mathrm{~nm} \\
\text { silicon }\end{array}$ & $\begin{array}{l}150 \mathrm{~nm} \\
\text { silicon }\end{array}$ & $\begin{array}{l}250 \mathrm{~nm} \\
\text { silicon }\end{array}$ & $\begin{array}{l}350 \mathrm{~nm} \\
\text { silicon }\end{array}$ & $\begin{array}{l}\text { No } \\
\text { silicon }\end{array}$ & $\begin{array}{l}50 \mathrm{~nm} \\
\text { silicon }\end{array}$ & $\begin{array}{l}150 \mathrm{~nm} \\
\text { silicon }\end{array}$ & $\begin{array}{l}250 \mathrm{~nm} \\
\text { silicon }\end{array}$ & $\begin{array}{l}350 \mathrm{~nm} \\
\text { silicon }\end{array}$ \\
\hline $0 / 9$ & Fail & 233 & 235 & 240 & 236 & Fail & 146 & 138 & 143 & 145 \\
\hline $1 / 8$ & 168 & 458 & 470 & 465 & 463 & 143 & 189 & 178 & 180 & 187 \\
\hline $2 / 7$ & 210 & 569 & 678 & 667 & 665 & 165 & 233 & 228 & 240 & 245 \\
\hline $3 / 6$ & 228 & 664 & 690 & 668 & 641 & 192 & 243 & 253 & 252 & 260 \\
\hline $4 / 5$ & 267 & 623 & 641 & 634 & 622 & 199 & 250 & 258 & 259 & 258 \\
\hline $5 / 45$ & 237 & 560 & 555 & 544 & 520 & 188 & 255 & 249 & 243 & 238 \\
\hline $6 / 3$ & 212 & 430 & 436 & 468 & 458 & 185 & 245 & 244 & 240 & 235 \\
\hline
\end{tabular}

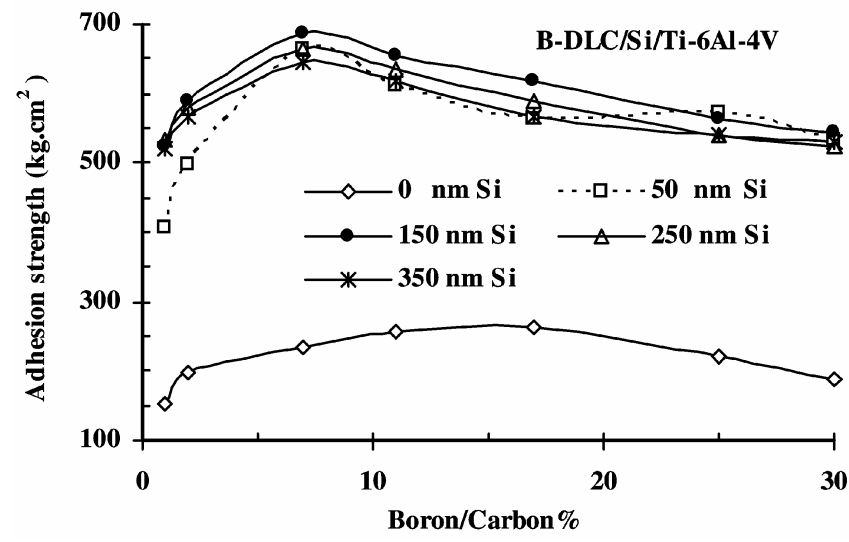

Figure 2. The adhesion strength as a function of both $\mathrm{B} / \mathrm{C} \%$ and silicon interfacial layer thickness on Ti-6Al-4V substrate at fixed 3/6 mTorrs of $\mathrm{CH}_{4} / \mathrm{Ar}$ partial pressures ratio.

dicted that the B-DLC films to Si contact failure occurred due to the presence of the native silicon dioxide layer (around $35 \AA$ of $\mathrm{SiO}_{2}$ ) that accumulated on the clean silicon surface in the first hour in air after surface cleaning. Moreover, the silicon layers deposited in our experiment were found to be amorphous as indicated by the X-ray diffraction patterns. Although the XRD scans did not show any titanium silicide peaks, other components of the alloys have shown to form silicides. However, the auger electron depth profiling using $2 \mathrm{keV}$ argon ion beam has shown that silicon diffuses through the Ti-6Al$4 \mathrm{~V}$ substrate skin into a deeper level as compared to that for grade $316 \mathrm{~L}$ stainless steel substrate. This can be attributed to the thermal processing of the substrates performed at $150^{\circ} \mathrm{C}$ for $1 \mathrm{~h}$ when the slugs were attached by the epoxy for the pull test experiments. The B-DLC films themselves have never torn up between the slug and the remaining part of the samples under the pull-test experiments. This particular result indicates that doping the DLC film with boron in the presence of hydrogen contents enhances its compactness and hence, the microstructural binding energy. The measurement of the adhesion strength of B-doped DLC on the single crystalline silicon substrate was infeasible because of the fragile nature of the silicon wafer substrate. It breaks before the metal slug pulls off the sample when high load is applied.

The percentage of boron in the DLC contents (B/C at \%) is calibrated with the applied d.c. power as seen in figure 1. The relationship between the adhesion strength and $\mathrm{B} / \mathrm{C}$ at $\%$ for B-DLC films deposited on the $\mathrm{Si} / \mathrm{Ti}-6 \mathrm{Al}-4 \mathrm{~V}$ substrates at different silicon layer thicknesses is illustrated in figure 2. It is very clear that introducing a thin silicon interfacial layer increases the adhesion strength to approximately four to five times the value with no silicon layer. Consequently, the silicon layer thickness is extremely an influential factor that substantially increases the adhesion strength. Also, it appears that introducing a silicon layer of thickness, $150 \mathrm{~nm}$, leads to the optimum value of the adhesion strength in the available range of $\mathrm{B} / \mathrm{C}$ at $\%$ in our experiment. The peaks of the adhesion strength curves are also found to occur at around $8 \%$ of B/C at \%. They then start to stabilize at around $600 \mathrm{~kg} / \mathrm{cm}^{2}$ for $\mathrm{B} / \mathrm{C}$ percentage ratios $>10 \%$ until they all saturate at a fixed adhesion value of $550 \mathrm{~kg} / \mathrm{cm}^{2}$. Similar relationships (see table 1) are shown in figure 3 for the B-DLC films deposited on $\mathrm{Si} / 316 \mathrm{~L}$ stainless steel substrates. Figures 2 and 3 indicate that the trend of adhesion strength curves for the first set of samples is characterized by a set of peaks centred at a specific $\mathrm{B} / \mathrm{C}$ at $\%$, while the second set of samples, follow approximately an exponentially increasing trend for the $\mathrm{B} / \mathrm{C}$ at $\%$ less than $20 \%$ and stabilizes at around $390 \mathrm{~kg} / \mathrm{cm}^{2}$ adhesion strength for percentages above $20 \%$. In other words, the adhesion strength is dependent on interfacial layer thickness as well as on the $\mathrm{B} / \mathrm{C}$ at $\%$ above $20 \%$.

In all cases the adhesion strength of the films on $\mathrm{Si} / \mathrm{Ti}-$ $6 \mathrm{Al}-4 \mathrm{~V}$ substrates has values that are much higher than those for $\mathrm{Si} / 316 \mathrm{~L}$ substrates. Clearly, figure 2 indicates that the adhesion strength exhibits a value of around $400 \mathrm{~kg} / \mathrm{cm}^{2}$ at a low B/C at \% (around $1 \%$ ), when $\mathrm{Si} / \mathrm{Ti}-6 \mathrm{Al}-4 \mathrm{~V}$ samples are used, while it adopts this value at the highest $\mathrm{B} / \mathrm{C}$ at $\%$ (around $30 \%$ ) with $\mathrm{Si} / 316 \mathrm{~L}$ as the substrates 
(see figure 3). Moreover, figure 2 demonstrates that the adhesion strength is the highest at silicon interfacial layer thickness of $350 \mathrm{~nm}$. However, it should be noted that the difference between the adhesion strength at a thickness of $350 \mathrm{~nm}$ is not remarkable, as compared to that at other interfacial layer thicknesses in the whole range, except for the $50 \mathrm{~nm}$ thickness.

The adhesion strength of B-DLC films deposited directly on titanium alloys (without silicon layer) has higher value compared with that for the films deposited on stainless steel, with no silicon interfacial layer, for $\mathrm{B} / \mathrm{C}$ at $\%<19 \%$ as seen in figures 2 and 3. However, the adhesion strength for the films deposited on stainless steel substrate (figure 3 ) is higher than that for films deposited on titanium alloy substrate at $\mathrm{B} / \mathrm{C}$ at $\%>19 \%$. It was predicted that boron in DLC films plays an important role in strengthening the

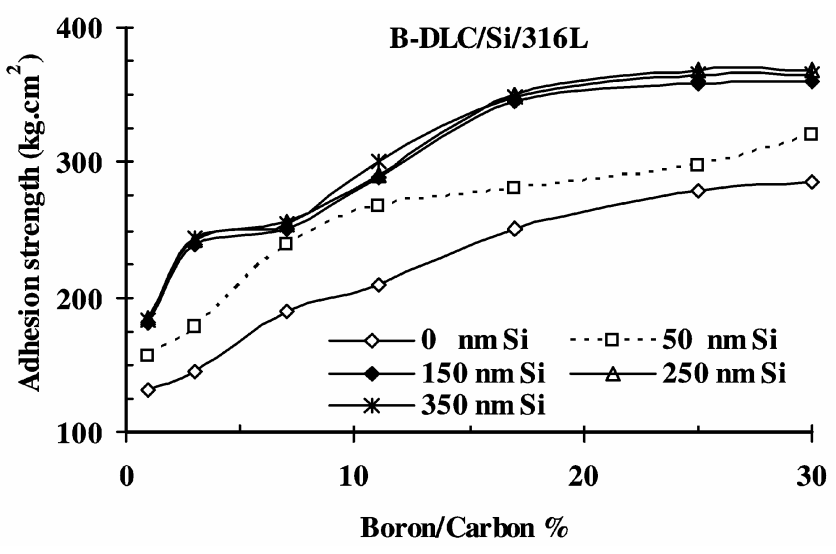

Figure 3. The adhesion strength as a function of both $\mathrm{B} / \mathrm{C}$ at $\%$ and silicon interfacial layer thickness on stainless steel alloy $(\mathrm{Si} / 316 \mathrm{~L})$ at fixed 3-6 mTorrs.

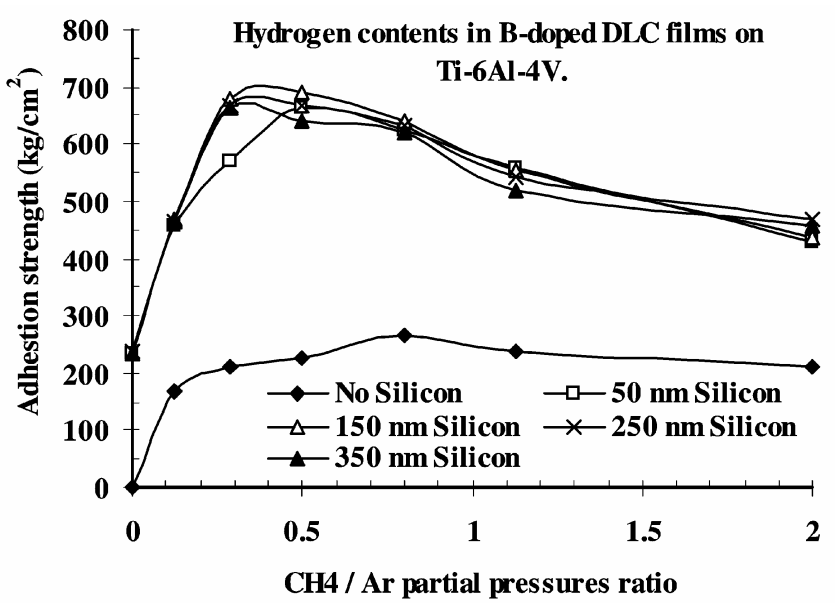

Figure 4. The adhesion strength of B-DLC films as a function of $\mathrm{CH}_{4} / \mathrm{Ar}$ partial pressure ratio (measured in mTorr) and silicon on interfacial layer thickness on titanium alloy at $8 \%$ of $B$ in DLC. physical interaction with titanium alloy substrate and hence, reducing the interfacial stress which ultimately increases the adhesion strength of films. This can be explained by the fact that, increasing the boron content in the DLC films increased the $s p^{3}$ bond content compared to the $s p^{2}$ bonds. The $s p^{3}$ content improves the hardness of films as they become closer to diamond in their hardness properties while the $s p^{2}$ content gives the films mechanical properties that are closer to amorphous carbon (Ianno et al 1995). Similar role for boron in the DLC films is observed in the case where stainless steel alloy is the substrate but with lower values.

Table 2 and figures 4 and 5 show the influence of $\mathrm{CH}_{4} / \mathrm{Ar}$ partial pressure ratio on the adhesion strength of B-DLC films deposited on $\mathrm{Si} / \mathrm{Ti}-6 \mathrm{Al}-4 \mathrm{~V}$ and $\mathrm{Si} / 316 \mathrm{~L}$ alloys, respectively, at constant $\mathrm{B} / \mathrm{C}$ at $\%(8 \%)$. The percentage of hydrogen content is qualitatively considered by correlating its value to the percentage of the gas carrier $\left(\mathrm{CH}_{4}\right)$ in the total gas pressure $\left(\mathrm{CH}_{4}+\mathrm{Ar}\right)$ in the deposition chamber. The B-DLC films produced by eliminating all the $\mathrm{CH}_{4}$ gas (i.e. no hydrogen association in the B-DLC films) from the sputtering process have failed under the scotch tape test rather than the pull test experiment as seen in table 2. A zero value for the adhesion strength is given to the failed samples. By comparing the results in figure 4 to those in figure 5, one may observe that, almost similar kind of curve trends for both substrates are produced. However, different values of adhesion strength are obtained for the two different substrates. Figure 4 reveals that the adhesion values could be as large as $700 \mathrm{~kg} / \mathrm{cm}^{2}$ for $\mathrm{CH}_{4} / \mathrm{Ar}$ partial pressure ratio of $0 \cdot 3$, and stabilize at $390 \mathrm{~kg} / \mathrm{cm}^{2}$ for all different values of silicon interfacial layer thickness, while it appears that the adhesion strengths for the films deposited on the stainless steel alloys exhibit their maximum values at $\mathrm{CH}_{4} / \mathrm{Ar}$ gas ratio of 0.5 and stabilize at around $250 \mathrm{~kg} / \mathrm{cm}^{2}$ for a wide range of gas ratios as shown by figure 5 . The value of the adhesion strength for the B-doped DCL films on $\mathrm{Si} / \mathrm{Ti}-6 \mathrm{Al}-4 \mathrm{~V}$ substrates decreases slowly as the ratio of $\mathrm{CH}_{4} / \mathrm{Ar}$ increases over $0 \cdot 3$ for all silicon interfacial layer thicknesses. All the relations in figure 4 have similar curve trends except for the $50 \mathrm{~nm}$ thickness which has the maximum at around $16 \%$ for the $\mathrm{B} / \mathrm{C}$ at $\%$. Compared to the $s p^{2}$ bonds that dominate the DLC, the $s p^{3}$ content improves the hardness of films and reduces the residual stress which increases the adhesion strength. In fact, the films are found to exhibit hardness properties resembling that of diamond in their hardness, while the $s p^{2}$ content gives the mechanical properties of films closer to those of amorphous carbon (Ianno et al 1995). Our results indicate that boron and hydrogen play similar role in DLC films deposited on stainless steel alloy substrate. However, the difference in the values of the adhesion strength was attributed to the role of interface with the substrate itself.

The increased $\mathrm{H}$-content is correlated with the increase in the $s p^{3} \mathrm{C}-\mathrm{H}$ hybridization in which it increases the $s p^{3}$ 
cross-linking region in the DLC films, which ultimately reduces the residual stress. However, since the $\mathrm{B}-\mathrm{C}$ bond is stronger than the $\mathrm{C}-\mathrm{C}$ bond and the $\mathrm{C}-\mathrm{H}$ bond is stronger than the $\mathrm{B}-\mathrm{H}$ bond, the $\mathrm{B}$ additive tends to bond with $\mathrm{C}$ rather than $\mathrm{H}$ in the DLC films in order to form $s p^{3}$ carbon neighbours and thus suppresses the formation of aromatic $s p^{2}$ bonds (He et al 2000). The incorporation of $\mathrm{B}$ additives in the DLC films up to $8 \%$ (at constant hydrogen content related to 3-6 mTorrs ratio for $\mathrm{CH}_{4}$ to Ar partial pressures) induces an increase in the $s p^{3}$ carbon bonding which causes an increase in the adhesion strength to its maximum value with optimal $150 \mathrm{~nm}$ silicon interfacial layer on titanium alloy. However, $20 \%$ of B additives, in the case of stainless steel alloy substrate are needed to produce the highest adhesion strength under similar experimental conditions.

Figure 6 shows the adhesion strength on the two types of substrates measured at fixed $\mathrm{B} / \mathrm{C}$ at $\%$ of $8 \%$, but for

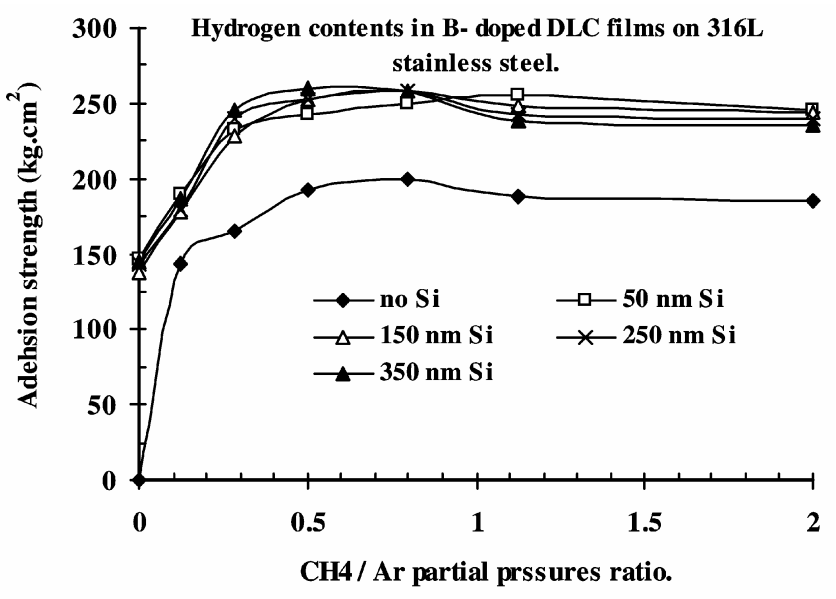

Figure 5. The adhesion strength of B-DLC films as a function of $\mathrm{CH}_{4} / \mathrm{Ar}$ partial pressure ratio and silicon on interfacial layer thickness on stainless steel alloy at $8 \%$ of B in DLC.

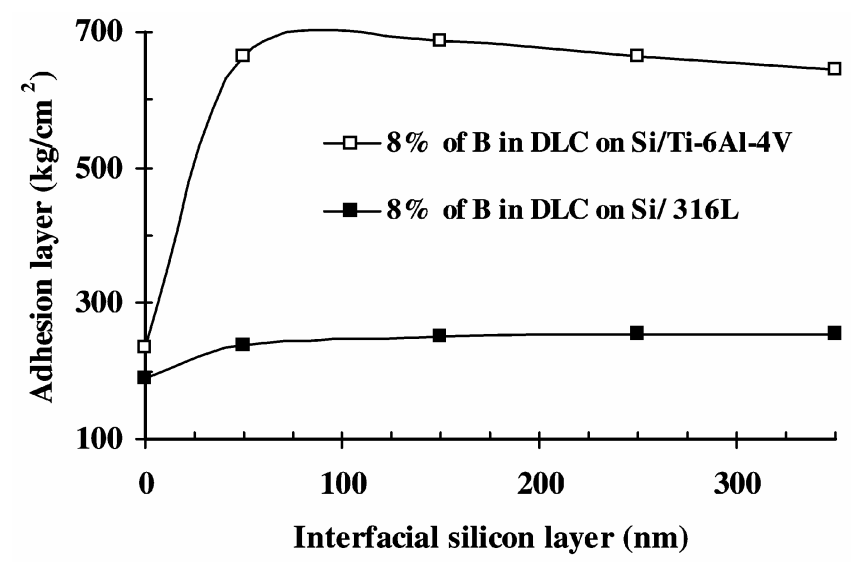

Figure 6. The adhesion strength vs silicon interfacial layer thickness at $8 \%$ of B in DLC films on both Ti6Al4V and grade 316L substrates. different silicon interfacial layer thicknesses. It is clear that B-DLC films on titanium substrate yield higher adhesion strength for all silicon interfacial layers, as compared to those of films deposited on stainless steel substrate. The highest value of the adhesion strength for the films deposited on titanium substrate appears at around $75 \mathrm{~nm}$ silicon layer, while for films deposited on stainless steel substrate, it increases slightly then stabilizes at a silicon interfacial layer thicknesses ranging between $50 \mathrm{~nm}$ and $300 \mathrm{~nm}$. This particular result can be attributed to the role that the sandwiched silicon plays in the cross-linking between the B-DLC films and the substrate as well as the $B$ diffusion in the silicon interfacial layer. Silicon diffuses differently in different substrates, therefore, produces different interlayer interactions and hence, produces different stress and surface hardness which ultimately affect the adhesion strength.

\section{Conclusions}

In summary, it has been found that doping DLC films with boron additives increases their adhesion strength in both grade $316 \mathrm{~L}$ stainless steel and Ti-6Al-4V titanium alloy substrates. As the silicon interfacial layers are introduced, the adhesion strengths gain further substantial enhancement. Our measurements indicate that a silicon interfacial layer of thickness, $75 \mathrm{~nm}$ and a boron/carbon $\%$ of $8 \%$ result in the best adhesion strength for B-DLC films deposited on titanium alloy substrates. However, at least $20 \%$ of $\mathrm{B} / \mathrm{C}$ at $\%$ with silicon interfacial layer of thickness, $150 \mathrm{~nm}$, is required to obtain good adhesive BDLC films on stainless steel alloy. Our study also demonstrates that the B-DLC films are good polymeric biomaterial coatings when deposited on stainless steel and titanium alloys whether silicon interfacial layers are used or not. However, our results indicate an enhancement of the adhesion strength when silicon interfacial layers are implemented. The percentage of boron content in the DLC film is directly related to the increase in the d.c. power applied to the $\mathrm{B}_{4} \mathrm{C}$ sputtering target gun. In fact, increasing the boron content to a moderate level increases the $s p^{3}$ carbon bonding, and hence, controls the adhesion strength by reducing the residual stress. It is believed that boron tends to diffuse into the silicon layer and hence releases the interfacial stress which enhances the interfacial layer adhesion. The boron content is not a crucial factor in determining DLC film properties. In fact, it is highly affected by the presence of hydrogen content, and hence, both correlate with each other to engineer films with optimum adhesive properties. Our striking result is that the increase in the hydrogen content is closely related to the increase in the ratio of $\mathrm{CH}_{4} / \mathrm{Ar}$ partial pressures as related to their flow rates. The hydrogenated B-DLC films deposited on $\mathrm{Si} / \mathrm{Ti}-6 \mathrm{Al}-4 \mathrm{~V}$ substrate are found to have the highest adhesion strength at $\mathrm{CH}_{4} / \mathrm{Ar}$ partial pressure ratio of $0 \cdot 3$, 
while a 0.5 ratio leads to the optimum value of adhesion strength for the films deposited on $\mathrm{Si} / 316 \mathrm{~L}$ substrates when both $\mathrm{CH}_{4}$ and $\mathrm{Ar}$ gases were pressurized at $9 \mathrm{mTorr}$. By eliminating the hydrogen carrier gas $\left(\mathrm{CH}_{4}\right)$ from the sputtering system, the source of hydrogen is eliminated and no hydrogen is introduced in the films. The B-DLC films with no hydrogen content was observed to fail under even the scotch tape test. This result indicates that hydrogen content plays a crucial role in strengthening the adhesion to the silicon layer deposited on both substrates, since hydrogen in the B-DLC films is found to act as a hydrogenating agent for the DLC films as well as for the underneath silicon layer. We hope that our striking results would be of great interest for the manufacturers of bone fixation equipments.

\section{References}

Ahmad A A 1996 Deposition and characterization of boron carbides, Ph D Dissertation, University of Nebraska-Lincoln, Nebraska, USA

Baker N P, Walter K C and Nasatasi M 1997 Materials Research Society, Fall Conference, Technical Report No. LAUR-97-4984 CONF-971201

Bentzon M D, Mogensen K, Barholmhansen C, Traeholt C, Holiday P and Eskildsen S S 1994 Surf. Coat. Technol. 68 651

Bonfield W and Tanner E 1997 Materials World 518

Box G E P, Hunter W G and Hunter J S 1978 Statistics for experiment (New York: John Wiley)

Brown H R 2000 Materials Forum 2449

Breusch S J and Kuhn K D 2003 Orthopade 141

Clark G C and Williams D F 1982 J. Biomed. Mater. Res. 16125

Czarnowska E, Wierzchon T, Maranda-Niedbala A and Kaczmarewicz E 2000 J. Mater. Sci. 1173

\section{Czernuszka J 1996 Materials World 4452}

Czyrska-Filemonowicz A, Moskalewicz T, Spiradek-Hahn K and Buffat P A 2003 Microsc. Micro. Anal. 9322

Davidson J A, Mishra A K, Kovacs P and Poggie R A 1994 Bio-Med. Mater. \& Eng. 4231

Davies O L 1971 The design and analysis of industrial experiments (New York: Hafner Publishing Co)

Deng J G and Braun M 1996 Dia. Relat. Mater. 4936

Franks J 1989 J. Vac. Sci. Technol. A7 2301

Gogolewski S and Mainil-Varlet P 1997 Biomaterials 18257

Grill A, Meyerson B S and Patel V V 1990 IBM J. Res. Develop. 3849

Harris W H 1994 Acta Orthop. Scand. 65113

Harris S J, Weiner A M, Tung S C, Simko S J and Militellc M C 1993 Surf. Coating Technol. 62550

Hauert R 2003 Dia. Relat. Mater. 12583

He X M, Li W Z and Li H D 1955 Mater. Sci. Eng. B31 269

He X M, Walter K C and Nasatasi M 2000 J. Phys.: Condens. Matter 12183

Ianno N J, Dillon R O, Ali A and Ahmad A 1995 Thin Solid Films 270275

Lee H J, Lee J K, Zubeck R, Smallen M and Hollars D 1992 Surf. Coating Technol. 54/55 552

Li D J and Gu H Q 2002 Bull. Mater. Sci. 257

Miyoshi K, Wu R L and Garscadden A 1992 Surf. Coat. Technol. 54/55 428

Ronkainen H, Likonen J, Koskinen J and Varjus S 1996 Surf. Coat. Technol. 7987

Sheeja D, Tay B K, Shi X, Lau S P, Daniel C, Krishnan S M and Nung L N 2001 Dia. Relat. Mater. 101043

Taube K, Grischke M and Bewilogua K 1996 Surf. Coat. Technol. 68662

Venugopalan R and Gaydon J 1999 A review of corrosion behaviour of surgical implant alloys, Perkin Elmer Instruments, Princeton Applied Research, Technical Review Note 99-01

Williams R L, Brown S A and Merritt K 1987 Biomaterials 9 181 